\title{
"Los pobres nos hacen amigos de Cristo" Ensayo para una fundamentación cristológica de la misión de la Compañía de Jesús
}

Martin Maier, S. J.

Stimmem der Zeit

München

En el año 2006, la Compañía de Jesús celebra un triple jubileo. En primer lugar, el 450 aniversario de la muerte de su fundador, san Ignacio de Loyola, quien murio en Roma, el 31 de julio de 1556. Recuerdo también los 500 años del nacimiento de san Francisco Javier, el 7 de abril de 1506, en Javier, Navarra, y del beato Pedro Fabro, nacido el 13 de abril de 1506, en Villaret, Saboya. El Padre Peter-Hans Kolvenbach, Superior General de la Compañía de Jesús, ha hecho un llamado a celebrar un "año jubilar" del 3 de diciembre del 2005 al 3 de diciembre de 2006, día de la muerte de Francisco Javier. El lema para este año jubilar es "amigos en el Señor". Se remonta a san Ignacio, quien describió asi al grupo de los primeros compañeros que se le unieron, en París. En este ensayo, intentaré fundamentar cristologicamente lo que significa "amistad en el Señor" y, desde los Ejercicios espirituales, relacionarla con la opción por los pobres.

\section{Introducción}

En el verano de 1529, ocurrió un escándalo en el barrio latino de París. Unos españoles muy respetados, Juan de Castro, Pedro de Peralta y Amador de Elduayen, abandonaron de repente los colegios en que vivían, repartieron sus pertenencias y libros entre los pobres, se mudaron al Hospital Saint-Jacques para indigentes y comenzaron a pedir comida de puerta en puerta. Sus amigos y paisanos los hicieron volver al barrio latino por la fuerza, y los obligaron, bajo contrato, a permanecer allí, hasta finalizar sus estudios. 
¿Qué había sucedido? Se llegó a saber que, tras el alboroto, estaba un estudiante español de nombre Iñigo López de Loyola. Les había dado a los tres estudiantes unos "ejercicios espirituales", y de esa forma los había movido a un cambio fundamental de vida. El cambio se hizo visible en su dedicación concreta al ideal de pobreza del evangelio. Entonces, en el colegio de Santa Bárbara se amenazó a Iñigo con una "sala", es decir, un azote público, por inducir a los estudiantes; e incluso se le quiso acusar de herejla ante el inquisidor del convento de los dominicos. Pero el inquisidor dejó que se calmaran las cosas, e Iñigo se escapó de recibir el castigo público, ganándose, por el contrario, al director del colegio de Santa Bárbara'.

Esto ocurrí mientras Ignacio de Loyola estudiaba en París y reunía en tomo a sí un círculo de amigos de siete estudiantes, que llegarían a ser el germen de la Compañía de Jesús. El centro de ese grupo era Ignacio. Pero su verdadero centro era Jesús, y, específicamente, el "Jesús pobre y humilde", tal como se les había hecho cercano e íntimo en los Ejercicios espirituales. Por eso, se llamaron a sí mismos "amigos en el Señor"2. Esa amistad no tenía significado en sí misma, sino que era apostólica, es decir, estaba dirigida hacia afuera. Ignacio tenía un proyecto que, en París, no estaba totalmente claro, pero sí tenía clara su orientación fundamental, "ayudar a las almas".

En este contexto, en este ensayo queremos fundamentar cristológicamente la misión de la Compañía de Jesús como expresión de esa "amistad en el Señor". A los textos originales de san Ignacio subyace la teología de Ignacio Ellacuría y Jon Sobrino. En un primer momento, analizaremos los discursos de despedida de Jesús, en el evangelio de Juan, donde él ya no llama siervos a sus discípulos, sino que los llama amigos. El pasaje posee una dinámica soteriológica y apostólica fundamental, la que, en un segundo momento, relacionaremos con la contemplación de la encarnación de los Ejercicios. Momento clave de esta contemplación es el "hagamos redención" de las tres divinas personas: su decisión de enviar al Hijo al mundo para la redención de la humanidad. Y en el movimiento de encarnación es crucial la pobreza. Se trata, en primer lugar, de una pobreza en el sentido de kénosis, como vaciamiento del mismo Dios, y en segundo lugar, en el sentido concreto de que el Hijo de Dios viene al mundo y vive en condiciones de pobreza. De esta forma, la opción por los pobres encuentra ya una fundamentación en los Ejercicios, e indirectamente también la lucha por la fe y la justicia, tal como la propone la Compañía de Jesús, en sus últimas congregaciones generales.

1. Cfr. Georg Schurhammer, Franz Xaver. Sein Leben und seine Zeit, Tomo primero. Europa 1506-1541, Friburgo, 1955, pp. 128-132.

2. Cfr. J. O'Malley, Die ersten Jesuiten, Wurzburgo, 1995, p. 47. 
En una carta a los jesuitas de Padua, escrita por Juan Alfonso de Polanco, por encargo de san Ignacio, éste desarrolla algunos elementos de una teología, o, con mayor precisión, de una cristología de la pobreza. En ella, los pobres aparecen como "vicarios de Cristo", tienen la capacidad de hacer "amigos del Rey Eterno". En Ignacio, pues, también aparece la intuición de que, aun después de la resurrección, la pasión de Cristo continúa a lo largo de la historia en los miembros de su cuerpo, que es la Iglesia. Al final volveremos sobre esto al relacionarlo con el teologoumenon del "pueblo crucificado", que acuño Monseñor Oscar Romero.

\section{La "cristología de la amistad" en el cuarto evangelio}

El texto bíblico clave para la fundamentación cristológica de la relación entre el envío apostólico y la "amistad en el Señor" se encuentra en el evangelio de Juan, en los discursos de despedida de Jesús. A sus discípulos, Jesús ya no los llama siervos, sino amigos (cfr. Jn 15, 1-17). Si se considera este texto en un contexto más amplio, se puede apreciar que el paso de la "servidumbre" a la "amistad" está enmarcado en una teologfa trinitaria de la misión. La amistad, a la que aquí se refiere Jesús, es expresión de su amor hacia los disclpulos. Y este amor refleja a su vez el amor entre Jesús y el Padre: "Como el padre me ama, asl los amo yo" (Jn 15, 9). Jesús le pide al Padre que cuando él se marche, envíe a los discípulos otro paráclito, el Espíritu de la Verdad (cfr. Jn 14, 16ss y 16,7). De esta manera, sus discípulos permanecerán en su amor.

Pareciera que Jesús pone una condición para permanecer en su amor, pues dice: “permanecerán en mi amor, si guardan mis mandamientos" (Jn 13, 34); y hay que recordar que Jesús ha resumido todos los mandamientos en uno solo: "les doy un mandamiento nuevo: jámense unos a otros! Como yo los he amado, así deben amarse entre ustedes" (Jn 13, 34). De ahí se desprende la aparente paradoja: condición para el amor es el amor. Pero precisamente, en eso se muestra la esencia del amor: es in-condicional, tiene su fundamento en sí mismo. Su más alta realización se da en la entrega de la vida: "no hay amor más grande que dar la vida por los amigos" (Jn 15, 13). Aquí está el quicio y el eje de toda la soteriología cristiana: en Jesús se muestra el amor de Dios hacia los hombres, y es tan grande que llega hasta la entrega del Hijo para la salvación de la humanidad: "pues tanto amó Dios al mundo que nos dio a su Hijo único" (Jn 3, 16). Este amor-entrega está íntimamente ligado con la amistad, que Jesús describe así: "ustedes son mis amigos, si cumplen lo que les mando" (Jn 15, 14). También aquí pareciera que Jesús pone una condición: ser amigo de Jesús supone hacer lo que él manda, lo cual en definitiva supondría volver a la relación señorsiervo. Pero esto es, precisamente, lo que niega Jesús: ya no llama siervos a sus discípulos, pues el siervo no sabe lo que hace su señor. 
Para Jesús, la amistad va unida al hecho de comunicar a sus discípulos todo lo que ha oído del Padre. Esencialmente, la amistad tiene que ver con la confianza; y a ello se añade la elección: "ustedes no me escogieron a mí; soy yo quien los escogí a ustedes y los he puesto para que vayan y produzcan fruto y ese fruto permanezca" (Jn 15,16). Con la metáfora del "fruto" se retoma la referencia a la parábola de la vid y los sarmientos: Jesús se compara a sí mismo con la vid, al Padre con el viñador y a los discípulos con los sarmientos que deben dar fruto: "mi Padre encuentra su gloria en esto: que ustedes produzcan mucho fruto, llegando a ser mis discípulos" (Jn 15, 8). Aparece aquí la "gloria Dei", que es tan importante en Ignacio, en relación con la realización de la misión y el seguimiento de Jesús. Todo sarmiento que no da fruto es cortado por el Padre, y todo sarmiento que da fruto es podado para que dé más fruto. Si se quiere, puede encontrarse en este "más" la dinámica ignaciana del "magis".

La relación entre la vid y los sarmientos es una imagen de la amistad. Los sarmientos sólo pueden dar fruto, si permanecen unidos a la vid. Y la amistad entre Jesús y sus discípulos está dirigida a dar fruto, pues por su propia esencia se dirige a la misión. Esta estructura trinitaria de la misión, a la que acabamos de aludir, en la teología joánica también aparece expresada en un pasaje del diario espiritual de san Ignacio: "En esto viniéndome otras inteligencias, es a saber, cómo el Hijo primero invió en pobreza a predicar a los apostoles, y después el Espíritu Santo, dando su espíritu y lenguas los confirmó, y así el Padre y el Hijo, inviando el Espíritu Santo, todas tres personas confirmaron la tal misión"3. Nótese que aquí se ponen en relación explícita misión y pobreza.

La amistad con Jesús no gira, pues, sobre sí misma, sino que ésta unida a la misión. A ésta pertenece también la pobreza. Y tiene que dar frutos. De lo que se trata es de hacer la voluntad de Dios, así como, en los Ejercicios, la contemplación de la encarnación desemboca en el hacer, y según la contemplación para alcanzar amor, el amor tiene que estar "más en las obras que en las palabras" (Ejercicios 230) .

\section{La contemplación de la encarnación}

La contemplación de la encamación con que comienza la segunda semana de los Ejercicios (nn.101-109) tiene un significado clave para la fundamentación cristologica de la misión. Sin forzar el texto, se pueden encontrar en ella los tres pasos fundamentales ver-juzgar-actuar, que se remontan al método de la JOC, la juventud obrera católica, y que son fundamentales también en el método de la teología de Ja liberación. En un primer momento, las personas divinas ven la situa-

3. Diario del 11 de febrero de 1544, en: Obras completas de San Ignacio de Loyola, Biblioteca de Autores Cristianos, Madrid, 1963, p. 322.

4. Los Ejercicios están citados según ibid., pp. 150-238. 
ción catastrófica en que se encuentran el mundo y la humanidad. En un segundo momento, juzgan (ino en el sentido de condenar!) que algo se debe hacer. Y en un tercer momento, toman la decisión de salvar a la humanidad, por medio de la encarnación del Hijo.

\subsection{La encarnación mueve hacia "abajo"}

En el primer preámbulo de la meditación, Ignacio invita a los ejercitantes a que asuman la perspectiva de las tres divinas personas, que "miraban toda la planicia o redondez de todo el mundo llena de hombres" (Ejercicios 102). En palabras actuales, se podría decir que Ignacio asume una perspectiva global, lo que describe más de cerca en el segundo preámbulo sobre la composición de lugar: "Aquí será ver la grande capacidad y redondez del mundo, en la qual están tantas y tan diversas gentes" (Ejercicios 103), diversidad que es plasmada plásticamente en el primer punto: "en tanta diversidad, así en trajes como en gestos: unos blancos y otros negros, unos en paz y otros en guerra, unos llorando y otros riendo, unos sanos, otros enfermos, unos nasciendo y otros muriendo, etcétera" (Ejercicios 106).

Después se dice, lapidariamente, cómo las divinas personas ven "todas las gentes en tanta ceguedad, y cómo mueren y descienden al infierno" (Ejercicios 106). Se puede discutir si Ignacio estaba realmente convencido de que todos los seres humanos van al infiemo, y quizás se puede pensar que Ignacio estaría describiendo la realidad de un mundo en cuanto no corresponde al plan de salvación de Dios. En cualquier caso, incluso hoy, la metáfora del infierno no es un desatino, pues muchos seres humanos deben vivir en situaciones sociales, políticas y también personales, las que, para ellos, hacen de la tierra un infiemo. Es lo que hacen los seres humanos sobre la faz de la tierra: "así como herir, matar, ir al infiemo, etc." (Ejercicios 108).

En el segundo preámbulo de la contemplación de la encarnación, Ignacio nos transporta de la perspectiva global a otra concreta: "la casa y aposentos de nuestra Señora, en la ciudad de Nazaret, en la provincia de Galilea" (Ejercicios 103). El ensamblaje de ambas perspectivas, la global y la local provinciana, impregna toda la contemplación. Ignacio parece haber sido muy consciente del peligro de que una visión excesivamente global hiciera perder de vista la realidad en su pequeñez y concreción. De ahí que pasa de la perspectiva del mundo a la de la provincia: de esta manera se insinúa ya que la obra salvífica de Dios comienza en lo pequeño.

Por último, el tercer paso de la contemplación lleva a la acción: "escuchar lo que dicen las personas divinas, es a saber: "hagamos redempción del género humano"' (Ejercicios 107). Este es el quicio decisivo de los Ejercicios. En este pasaje, el texto español original reza de manera poderosa y sintética: "hagamos redención". Las divinas personas son movidas a compasión por el sufrimiento y 
el desastre que ven. Y están completamente de acuerdo: "No podemos permitir que esto continúe así. Tenemos que hacer algo". Deciden entonces la encarnacíón de la segunda persona "para redimir al género humano". A esta decisión sigue inmediatamente la misión del ángel Gabriel a Nuestra Señora: la encamación comienza en un lugar pequeño y pobre de Nazaret. Con ello se diseña el movimiento fundamental de la encarnación, de arriba hacia abajo, de la riqueza de Dios a la pobreza humana, de la omnipotencia hacia la impotencia.

Este movimiento fundamental de la encarnación corresponde a la opción por los pobres, que, en un primer momento, no es puesta en marcha por la realidad social, sino que tiene su origen directamente en Dios. Es lo que dice san Pablo, cuando escribe a los corintos: "Por ustedes se hizo pobre, siendo rico, para hacerlos ricos con su pobreza" $(2$ Cor 8, 9). Jon Sobrino recalca una doble humillación de Dios en la encamación: "Dios se ha mostrado a este mundo, ha entrado en nuestra historia y se ha vuelto parte de nuestra humanidad en los débiles y pequeños, en los pobres y oprimidos. Nuestro Dios es un Dios hecho carne, que se ha abajado doblemente: hacia lo humano y hacia lo débil y pobre de lo humano"s.

\subsection{El seguimiento del Jesús pobre y humilde}

Con ello se ha diseñado el programa para la segunda semana de los Ejercicios. Su finalidad es llevar al ejercitante al seguimiento "del Jesús pobre" para colaborar en su obra de salvación. Lo invita, así, al final de la contemplación de la encamación, a contemplar a la sagrada familia, "cómo es el caminar y trabajar, para que el Señor sea nascido en summa pobreza, y a cabo de tantos trabajos, de hambre, de sed, de calor y de frío, de injurias y afrentas, para morir en cruz; y todo esto por mr" (Ejercicios 116).

Especial significado para la comprensión de la pobreza tiene en san Ignacio su dimensión personal: Jesús ha vivido en pobreza, y en esa pobreza quiere asemejársele él. De ahí la llamada del Rey eternal: "quien quisiere venir conmigo, ha de ser contento de comer como yo, y así de beber y vestir, etc." (Ejercicios 93). Y de acuerdo con esto dice así la respuesta a Cristo: "yo hago mi oblacion... de imitaros en pasar todas injurias y todo vituperio y toda pobreza, así actual como spiritual" (Ejercicios 98).

La teología de la liberación, por su parte, al abordar el tema de la pobreza ha enfatizado de manera especial su dimensión dialéctica. La pobreza se define como lo contrario a la riqueza, y se recalca también el contexto causal entre pobreza y riqueza. Ignacio Ellacuría, para comprender la pobreza de las bienaventuranzas, en el evangelio de Lucas, dice: "Los pobres que aquí se nombran

5. Jon Sobrino, "Gemeinschaft mit den gekreuzigten Voblkem, um sie vom Kreuz abzunehmen", en: Ludwig Bertsch (compilador), Was der Geist den Gemeinden sagr. Bausteine einer Ekklesiologie der Ortskirchen, Friburgo, 1991, p. 115. 
son, ante todo, los pobres materiales, que se definen por sus contrarios, los ricos; $y$, más en general, los que son pobres injustamente, como resultado de la acción de los poderosos"6. Pues bien, la dimensión dialéctica de la pobreza también está presente en la contemplación de las dos banderas. En las redes y cadenas que los demonios lanzan para la perdición de la humanidad, está en primer lugar, la "cobdicia de riquezas"; a ella le sigue el "vano honor" del mundo, y finalmente, la soberbia desenfrenada ( $c f r$. Ejercicios 142). Y estos tres estadios son presentados en relación dialéctica con la pobreza, las calumnias y el desprecio, y la humildad.

La dimensión dialéctica de la pobreza y la dimensión personal de asemejarse a Cristo convergen en la tercera manera de humildad: "quando... por imitar y parescer más actualmente a Christo nuestro Señor, quiero y elijo más pobreza con Christo pobre que riqueza, oprobrios con Christo lleno dellos que honores, y desear más de ser estimado por vano y loco por Christo que primero fue tenido por tal, que por sabio ni prudente en este mundo" (Ejercicios 167).

Que esta pobreza tiene consecuencias bien concretas, aparece con claridad en el texto "para emendar y reformar la propia vida y estado", donde se pide al ejercitante que reflexione acerca de las riquezas: "quánta debe tomar para su familia y casa, y quánta para dispensar en pobres y en otras cosas pías" (Ejercicios 189).

De igual manera, en las reglas para el "ministerio de distribuir limosnas" (Ejercicios 344) vuelve a aparecer Jesús como la norma y el criterio de conducta: "por las razones ya dichas y por otras muchas, siempre es mejor y más seguro, en lo que a su persona y estado de casa toca, quanto más se cercenare y disminuyere, y quanto más se acercare a nuestro summo pontffice, dechado y regla nuestra, que es Christo nuestro Señor" (Ejercicios 344). Además, san Ignacio cita el concilio de Cartago, que, bajo la presencia de san Agustín, "determina y manda que la suppeléctile (mobiliario) del obispo sea vil y pobre". Y menciona, finalmente, como ejemplo de matrimonio, a san Joaquín y santa Ana, quienes dieron un tercio de sus haberes a los pobres, otro tercio para el ministerio y el servicio del templo y el resto para el sustento propio y de su familia.

Añadamos un pequeño detalle que, en san Ignacio, bien puede ser interpretado en el sentido de una "opción preferencial por los pobres". Se encuentra en la meditación sobre la purificación del templo y la expulsión de los mercaderes. En los dos primeros puntos, san Ignacio comenta el texto según el evangelio de Juan. Pero en el tercer punto, dice: "A los pobres que vendían palomas mansamente dixo: quitá estas cosas de aquí y no quieráys hacer mi casa cassa de mercadería" (Ejercicios 277). San Ignacio recalca, pues, la diferente manera de tratar Jesús a los negociantes y cambistas con azotes, y a los vendedores de palomas, mansamente.

6. Ignacio Ellacuria, Escriros teologicos, Tomo II, San Salvador, 2000, p. 427. 


\section{La carta a los jesuitas de Padua}

El 7 de agosto de 1547, bajo la dirección de san Ignacio, escribió Polanco una carta a los jesuitas de Padua ${ }^{7}$, quienes estaban en dificultades económicas y experimentaban la pobreza, en sus propios cuerpos. En ella se puede encontrar una pequeña obra maestra de una teología de la pobreza. Y ante todo, resuena la dimensión personal de la pobreza: "vimos, entre otras cosas, el amor de la pobreza que habeís elegido por amor de Jesucristo pobre".

San Ignacio llama a la pobreza una gracia y un don de Dios, y lo fundamenta en primer lugar con una cita del Antiguo Testamento: "pobreza y riqueza, todo viene del Señor" (Sir 11, 14). Sigue después una fundamentación cristológica, en la línea de la contemplación de la encarnación: "siendo (la pobreza) tan amada de Dios, cuanto lo muestra su Unigénito, que, dejando el trono real, quiso nacer y crecer en ella". Pero no sólo en la encamación, sino también en la vida terrestre de Jesús, la pobreza juega un rol central: "no sólo la amó en vida, padeciendo hambre, sed, y no teniendo donde reclinar la cabeza; más también en la muerte, queriendo ser despojado de sus vestiduras, y que todas sus cosas, hasta el agua en la sed, le faltase". San Ignacio vuelve a recalcar la doble dimensión de la pobreza de Cristo, en la encarnación y en la forma de vida del Jesús terreno, como bien dice Sobrino, en la cita anterior.

$\mathrm{Y}$ aduce todavía otro argumento en favor de la pobreza, cómo la aprecia Dios: "viendo cómo los escogidos amigos suyos, sobre todo en el Nuevo Testamento, comenzando por su santísima Madre y los apóstoles y siguiendo por todo lo que va de tiempo hasta nosotros, comúnmente fueron pobres". De nuevo, san Ignacio acentúa que aquf se trata de una imitación de Cristo.

Fundamenta después con citas, tanto del Antiguo como del Nuevo Testamento, el lugar central que los pobres tienen ante Dios: "Son tan grandes los pobres en la presencia divina, que principalmente para ellos fue enviado Jesucristo a la tierra: 'por la opresión del mísero y del pobre ahora - dice el Señor- habré de levantarme'; y en otro lugar: 'para evangelizar a los pobres me ha enviado', lo cual recuerda Jesu Cristo, haciendo responder a San Juan: 'los pobres son evangelizados"".

En este contexto, recordemos unas vigorosas palabras de Juan Pablo II. En un discurso durante su visita a Canadá, en 1987, el papa dijo, en una paráfrasis profética de la parábola del juicio final, en el evangelio de Mateo 25, que los pueblos pobres son los que juzgarán a los pueblos ricos. Pues bien, algo parecido aparece en la carta de san Ignacio: "Tanto los prefirí a los ricos, que quiso Jesucristo elegir todo el santísimo colegio de entre los pobres, y vivir y conversar con ellos, dejarlos por príncipes de su Iglesia, constituirlos por jueces sobre

7. Obras Completas, pp. 700-704. 
las doce tribus de Israel, es decir, de todos los fieles. Los pobres serán sus asesores. Tan excelso es su estado".

Y a continuación viene el texto del que hemos tomado el título de este ensayo, y que fue retomado por la Congregación General XXXIV, al que ésta definió como texto profético: "La amistad con los pobres nos hace amigos del Rey eterno. El amor de esa pobreza nos hace reyes aun en la tierra, y reyes no ya de la tierra, sino del cielo. Lo cual se ve, porque el reino de los cielos está prometido para después a los pobres, a los que padecen tribulaciones, y está prometido ya de presente por la Verdad inmutable, que dice: 'Bienaventurados los pobres de espíritu, porque de ellos es el reino de los cielos', porque ya ahora tienen derecho al reino".

En medio de tan alta estima teológica de la pobreza es típico de san Ignacio poner de relieve, sobriamente, sus aspectos amargos -y así lo hace también la teología de la liberación-, al distinguir entre pobreza como "infancia espiritual" y como "carencia injusta de lo necesario para vivir". De igual manera, habla san Ignacio de pobres voluntarios y de pobres a la fuerza. Y con una cita de Séneca, fundamenta por qué la pobreza va unida a un gozo especial: "los pobres ríen más de placer por no tener solicitud ninguna. Y bien lo demuestra la experiencia en los mendigos vulgares, que, si advirtiésemos sólo su contento, veríamos que viven más alegres y satisfechos que los grandes comerciantes, magistrados, príncipes y otros grandes personajes". Esta es, todavfa hoy, la experiencia de muchas personas, que están en relación cercana a personas pobres.

Termina la carta con unas reflexiones, que ayudan a revisar el propio estilo de vida: "aquellos que aman la pobreza, deben amar el séquito de ella, en cuanto de ellos dependa, como el comer, vestir, dormir mal y el ser despreciado. Si, por el contrario, alguno amara la pobreza, mas no quisiera sentir penuria alguna, ni séquito de ella, sería un pobre demasiado delicado y sin duda mostraría amar más el título que la posesión de ella, o amarla más de palabra que de corazón".

En estas palabras resuenan con claridad las reglas de la contemplación para alcanzar amor: el amor hay que ponerlo más en obras que en palabras. La pobreza exige un cambio en la vida personal, tal como sucedió con los tres estudiantes españoles en París, de lo cual hablamos al principio.

\section{5. "Coloquio con el pueblo crucificado"}

La Congregación General 34, en su decreto fundamental "Servidores de la Misión de Cristo", cita a Jerónimo Nadal', según el cual para san Ignacio, Jesucristo, por la cruz, está presente en el sufrimiento del mundo, por el que muri6: "Cristo ha resucitado de entre los muertos y ya no muere (Rom 6, 9), pero sufre

8. MHSI, Mon. Ign. Font Narr., I 314. 
aún en sus miembros y sigue llevando la Cruz. Por eso pudo decir a Pablo: ‘ $i$ Por qué me persigues"' . En estas breves frases se esconde toda una teología del cuefpo de Cristo en su Iglesia, que sigue viviendo y sufriendo en la historia. También el arzobispo salvadoreño Oscar Romero, quien fue asesinado el 24 de marzo de 1980 por su profética defensa de los pobres, comprendió el sufrimiento de su pueblo desde esta perspectiva ${ }^{10}$, y creó la metáfora del "pueblo crucificado". En un primer momento, la afirmación es sorprendente. ¿Cómo puede alguien imaginarse la crucifixión de todo un pueblo? - y hay que recordar que en América Latina el concepto "pueblo" designa sobre todo a seres humanos sencillos y pobres. Es cierto que Romero utiliza la expresión "pueblo crucificado" en un sentido simbólico-imaginativo, pero la realidad tras el concepto es muy real.

Los cánticos del siervo de Yahvé del profeta Isaías son, para Monseñor Romero, una mediación hermenéutica entre el sufrimiento colectivo del pueblo y la cruz de Cristo. En el libro de Isaías están insertados cuatro textos sobre un misterioso siervo de Yahvé, que sufre inocentemente, y por medio del cual Dios realiza su plan de salvación. Romero hace caer en la cuenta que los exegetas no se ponen de acuerdo sobre si el siervo se refiere a un individuo o al pueblo de Israel que sufre en el exilio. Monseñor Romero ve el sufrimiento del pueblo salvadoreño en el espejo del maltratado siervo de Yahvé. De él se dice que lo dejaron tan maltrecho, que ya no parece hombre y causa espanto $-y$ de manera tan horrenda aparecieron maltratados muchos cadáveres a las orillas de caminos y en basureros a finales de la década de 1970 y principios de la de 1980.

Del siervo de Yahvé se dice también que "fue tratado como culpable por causa de nuestras rebeldías y fue aplastado por nuestros pecados" (Is 53, 5). El siervo sufre por causa de otros; la culpa de otros es descargada sobre él. Y esto ha ocurrido en El Salvador: muchos inocentes se convirtieron en víctimas. Sin embargo, al final, los cantos del siervo toman un giro sorprendente: "él soportó el castigo que nos trae la paz y por sus llagas hemos sido sanados" (Is 53, 5). Así como del siervo sufriente emana salvación, también para Monseñor Romero, el pueblo sufriente es lugar de la salvación, producida por Dios.

Los cantos del siervo fueron una clave de interpretación de la comunidad cristiana primitiva para reconocer el plan salvador de Dios, en el aparente fracaso de Jesús crucificado. Jesús fue identificado con el Siervo de Yahvé. Por su parte, Monseñor Romero se apoya también - como lo hizo Nadal o más bien san Ignacio- en la comprensión paulina de la Iglesia como Cuerpo de Cristo, que vive en la historia. Cuando Pablo escucha la voz de Jesús: "Saulo, Saulo, ¿por qué me persigues?" (Hech 9, 4), Jesús se identifica con los cristianos perseguidos.

9. Congregación General XXXIV, n. 26.

10. Ver Martin Maier, Oscar Romero, Mistica y lucha por la justicia, Barcelona, 2005. 
Monseñor Romero relaciona la persecución de la Iglesia en El Salvador con el mismo Cristo, "pues quien toca a sus cristianos toca a Cristo". Se da, pues, una doble identificación del siervo, tanto con Cristo como con la Iglesia: "Es un personaje misterioso, pero los intérpretes llegan a identificarlo con Cristo, pero un Cristo no sólo individuo sino un Cristo comunidad. El siervo de Yahvé es Cristo y la comunidad cristiana es el pueblo cristiano"'".

Desde esta perspectiva, Romero pone en relación la pasión del pueblo salvadoreño con el siervo sufriente y con el Cristo crucificado. En su homilía del domingo de ramos de 1978, por primera vez, habla expresamente del "pueblo crucificado". "Sentimos en el Cristo de la Semana Santa con su cruz a cuestas, que es el pueblo que va cargando también su cruz. Sentimos en el Cristo de los brazos abiertos y crucificados, al pueblo crucificado, pero que desde Cristo, un pueblo que crucificado y humillado, encuentra su esperanza:'Te he enseñado a dar palabras de consuelo, has aprendido en el dolor a consolar a los demás'"'l?

En el discurso que pronunció en Lovaina, con ocasión de conferírsele el doctorado Honoris Causa en teología, el 2 de febrero de 1980, pocas semanas antes de su asesinato, Monseñor Romero se refirió, en formulación muy densa, a la identificación del pueblo torturado, el siervo sufriente y el Hijo de Dios crucificado: "La verdadera persecución se ha dirigido al pueblo pobre, que es hoy el cuerpo de Cristo en la historia. Ellos son el pueblo crucificado, como Jesús, el pueblo perseguido como el Siervo de Yahvé. Ellos son los que completan en su cuerpo lo que falta a la pasión de Cristo". La última frase hace alusión a unas palabras de san Pablo en su carta a los Colosenses: "me alegro por los padecimientos que soporto por ustedes; así completo en mi came lo que falta a los sufrimientos de Cristo" (Col 1, 24). En forma enigmática, Pablo dice aquí que algo le falta al sufrimiento de Cristo y que debe ser completado. De esa forma, pone en relación su propio sufrimiento con el sufrimiento de Cristo. De igual manera, relaciona Monseñor Romero el sufrimiento del pueblo crucificado con Cristo.

En la cruz se manifiesta la maldad de la humanidad, el pecado del mundo. Pero también se muestra en ella el amor perdonador y salvador de Dios. Por eso, san Ignacio anima en los Ejercicios a ponerse siempre ante la cruz y hacer un coloquio con el Cristo crucificado. Dice textualmente: "El coloquio se hace propiamente hablando, así como un amigo habla a otro, o un siervo a su Señor" (Ejercicios 54). Vemos de nuevo cómo, en este momento decisivo, aparece la metafora de la amistad. Y sobre lo que hay que meditar son tres preguntas: "lo que he hecho por Christo, lo que hago por Christo, lo que debo hacer por Christo" (Ejercicios 53).

11. VIII, p. 143. Las homilias están citadas según la Colección homillas y Diario de Mons. Oscar Arnulfo Romero, 9 tomos, San Salvador, 2000. La cifra romana indica el tomo y la arábica el número de página.

12. IV, p. 67. 
Inspirado por Monseñor Romero, Ignacio Ellacuría reinterpretó creativamente este coloquio con los pueblos crucificados. Al final de una conferencia en Vallađolid (España), se dirigió a la audiencia con esta petición: "Lo único que quisiera [...] son dos cosas: que pusieran ustedes sus ojos y su corazón en esos pueblos, que están sufriendo tanto - unos de miseria y hambre, otros de opresión y represion - y después (ya que soy jesuita), que ante ese pueblo crucificado hicieran el coloquio de san Ignacio en la primera semana de los Ejercicios, preguntándose: ¿qué he hecho yo para crucificarlo?, ¿qué hago para que lo descrucifiquen?, ¿qué debo hacer para que ese pueblo resucite?"13

Este coloquio, sin embargo, no debe quedar en meditación puramente religiosa, sino que debe llevar a la acción: "el amor se debe poner más en las obras que en las palabras" (Ejercicios 230). Y de ahí, la conclusión: la amistad con los pobres, en situación de injusticia, miseria y opresión, debe traducirse históricamente en lucha por la justicia. Para Ignacio Ellacuría, lo esencial del cristianismo consiste en "el amor de Dios en el amor a los hombres, la justicia como lugar de realización del amor en un mundo de pecado"14. Y esta unidad entre fe y justicia se fundamenta en la unidad entre amor al prójimo y amor a Dios, así entendida. El amor al prójimo corresponde a la justicia y el amor a Dios a la fe. Para Ellacuria, la consecuencia es que "la justicia cristiana es el lugar donde se realiza el amor de los hombres, y allí donde se muestra la presencia del amor de Dios tal como se ha revelado en Jesucristo"ls.

Finalmente, hay que precisar de forma más concreta quién es el projimo a quien se dirije el amor cristiano. Ellacuría encuentra la respuesta en la parábola del buen samaritano: "La parábola muestra que es el samaritano quien verdaderamente ama a Dios, porque ama y actúa en favor del necesitado, que es su prójimo porque está en situación de desamparo (el prójimo es entonces el desamparado o, visto desde el otro lado, se es prójimo precisamente respecto del oprimido"'6). Y el otro pasaje biblico clave en este contexto es la parábola del juicio final del evangelio de Mateo $(25,31-46)$. Ellacuría, desde el tercer mundo, lo interpreta como "el lugar donde habitan los pobres de la tierra y, tras los pobres de la tierra, el escondido pobre de la historia, que ha prometido estar tras el hambriento, el sediento, el encarcelado, el oprimido..."17. La parcialidad del amor cristiano en favor de los pobres, tiene como modelo a Jesús: "Jesús amó a todos, pero se situó del lado del oprimido y desde allí luchó enérgicamente pero

13. Ignacio Ellacurfa, Escritos teologicos, Tomo III, San Salvador, 2002, p. 602.

14. Ignacio Ellacurfa, Conversión de la Iglesia al reino de Dios para anunciarlo y realizarlo en la historia, San Salvador, 1985, p. 209.

15. Ignacio Ellacurfa, "Fe y justicia", en Ignacio Ellacurfa et al., Fe, justicia y opción por los oprimidos, Bilbao, 1980, p. 56.

16. Ibid., p. 48.

17. Ignacio Ellacuria, Conversión de la Iglesia, p. 294. 
amorosamente contra los opresores"18. Por ello, la lucha por la fe y la justicia es la forma histórica del amor cristiano.

\section{Conclusión}

En este ensayo, hemos partido del ideal evangélico de pobreza, como resultado o consecuencia concreta de los Ejercicios. En una contemplación de la "cristología de la amistad joánica" queda claro que la misión brota de la amistad con Jesús, y la misión para san Ignacio está unida, sustancialmente, con la pobreza. Esto lo basa en una perspectiva teológica de encarnación, tal como aparece en los Ejercicios, en la contemplación de la encarnación: el Hijo recorre el camino de la abundancia divina hacia la pobreza humana, en el sentido de la kénosis y se vuelve hombre en condiciones sociales de pobreza. San Ignacio muestra, en la carta a los jesuitas de Padua, que la amistad con los pobres conlleva a ser amigos de Jesús, porque ellos son sus representantes. A ellos se les aplica, en sentido estricto, el título de "vicarios de Cristo". Cuando los pobres son los representantes de Cristo en el mundo y la historia, entonces, su sufrimiento hace presente la cruz de Cristo, en la historia. Esto llevó al Monseñor Romero a hablar del "pueblo crucificado". En la unión de la teología joánica de la amistad y la teología ignaciana de la vicariedad de los pobres, podemos realizar, siguiendo a Ignacio Ellacuría, el diálogo con el crucificado también como diálogo con el pueblo crucificado, "así como un amigo habla a sus amigos". Desde esta amistad con los pobres aparece con claridad que la lucha por la fe y la justicia es la expresión contemporánea de la misión de la Compañía de Jesús.

18. Ibid., p. 203. 